\title{
EL INTERES SUPERIOR DEL ESTUDIANTE: UNA APROXIMACIÓN A SU CONTENIDO, EVALUACIÓN Y DETERMINACIÓN
}

\author{
MICHAEL ESPINOZA COILA*
}

\section{RESUMEN}

El presente artículo, da a conocer una breve investigación que tuvo por objetivos: definir el interés superior del estudiante, establecer su objetivo, señalar sus dimensiones, explicar la relación que tiene con la educación, y explicar cómo evaluar y determinar el interés superior del estudiante; mediante el método jurídico, se define el interés superior del estudiante, como aquel que tiene como consideración primordial atender el interés del estudiante en todas las medidas concernientes a los estudiantes que tomen las universidades, con el objetivo de garantizar el disfrute pleno y efectivo del derecho a la educación, para ello se manifiesta en tres dimensiones: como derecho sustantivo, principio jurídico interpretativo y norma de procedimiento; y siendo un concepto parabólico, mantiene una conexidad con los derechos fundamentales reconocidos en la Constitución y el Derecho Internacional de los Derechos Humanos y los principios de la Ley Universitaria; para su aplicación concreta se requiere la evaluación y determinación de su contenido, que consiste en valorar y sopesar todos los elementos o circunstancias necesarias para tomar una decisión en una determinada situación para los estudiantes, y desarrollar procesos estructurados con reglas y garantías.

PALABRAS CLAVE: Principio, educación, estudiante, derecho, norma, procedimiento.

\section{ABSTRACT}

In this article, it gives an understanding of a brief investigation that aimed to: define the interest of the student, to set a goal, noting its size, to explain the relationship with education, and explain how to evaluate and determine the best interests of the student; through the legal method, the interest of the student is defined as having a primary consideration to attend a student's interest in all actions concerning students taking university, with the guaranteed objective to ensure the full and effective enjoyment of the right to education, for it is manifested in three dimensions: as substantive law, the interpretative legal principle and rule of procedure, and being a parabolic concept, maintains a connection with the fundamental rights recognized by the Constitution and international human rights law and the principles of the University Act; for the complete application it is required the evaluation and determination of its content, which is to assess and weigh all the elements or necessary circumstances to make a decision in a given situation for students, and develop rules and guarantees structured processes.

KEYWORDS: Beginning/Top, education, student law, law, rule, procedure

\footnotetext{
* Estudiante de la Escuela Profesional de Derecho. Círculo de Investigación Líderes Optimistas Revelando Derecho (CILORD) e Instituto de Investigación de la Facultad de Ciencias Jurídicas y Políticas de la Universidad Nacional del Altiplano de Puno. Correo electrónico: micnous@gmail.com
} 


\section{INTRODUCCIÓN}

La presente investigación tiene por origen el artículo $5.14^{\circ}$ de la Ley $\mathrm{N}^{\circ} 30220$ «Ley Universitaria», referido al interés superior del estudiante, $\mathrm{y}$ como antecedente indirecto el interés superior del niño artículo contenido en el artículo $3.1^{\circ}$ de la Convención sobre los Derechos del Niño.

La importancia del tema estriba en la comprensión y observancia del principio del interés superior del estudiante a fin de garantizar el derecho a la educación, y promover un cambio de actitud que favorezca el pleno respeto de los derechos de los estudiantes, en la elaboración y aplicación de medidas por los órganos de gobierno, docentes y personal no docente, así como decisiones que afecten individual o grupalmente a los estudiantes, $y$ estudiantes universitarios en general.

La razón principal que justifica la investigación, es la necesidad de orientar las decisiones jurisdiccionales y administrativas (autoridad educativa) a la hora de resolver casos concretos, mediante criterios que ayudan en evaluación y determinación del interés superior del estudiante. Otra de las razones para aventurarnos a desarrollar el contenido del mencionado principio, es la ausencia de fuentes documentales que aborden el interés superior del estudiante.

En esta ocasión, respondemos a los siguientes enunciados del problema: ¿qué es el principio del interés superior del estudiante? ¿cuál es su objetivo? ¿cuáles son sus dimensiones?, ¿cuál es su relación con los derechos fundamentales y los principios de la Ley Universitaria? y ¿cómo evaluar y determinar el interés superior del estudiante?; en cuanto a los objetivos de la investigación, estos son: (a) definir el interés superior del estudiante, (b) establecer el objetivo del interés superior del estudiante (c) señalar las dimensiones del interés superior del estudiante, (d) explicar la relación del interés superior del estudiante con los derechos fundamentales y los principios de la Ley Universitaria, y (e) explicar cómo evaluar y determinar el interés superior del estudiante; tratándose de un trabajo doctrinal no es necesario la hipótesis de investigación.

\section{MATERIALES Y MÉTODOS}

La investigación de tipo doctrinal (documental), aplicó el método jurídico; el proceso investigación tuvo las siguientes etapas:(a) planteamiento del problema, (b) plan de acercamiento a la solución, (c) información metódica, (d) construcción de una solución y (e) formulación de soluciones; y tiene por población el interés superior del estudiante (unidad de estudio), y se usó técnicas de interpretación dogmática, y exegética, con instrumentos de fichaje textual para la revisión del material bibliográfico.

\section{RESULTADOS Y DISCUSIÓN}

3.1. Estado de la cuestión: El ápice del interés superior del estudiante es el mismo estudiante; por su carácter omnímodo en la presente investigación es conveniente anotar su definición y su estatus a partir de una somera exposición de la realidad educativa nacional.

La educación peruana es el resultado de la sinergia del pensamiento español o colonial, la francesa y la norteamericana con el desarrollo capitalista, mediante la importación de capitales, técnicos e ideas yanquis (Cf. MARIÁTEGUI, 1973:159), lo cual devino en una proficua globalización del mercado, que ha permeado el sistema educativo peruano. Está realidad educativa, fue acotada por varias construcciones teóricas: la tradicional, la activa, la tecnicista, la personalizada, de la equidad y la solidaridad, y la histórico-crítica (pedagogía crítica). Este último aterriza en América Latina con las propuestas de Paulo Freire con el movimiento de la educación popular, la pedagogía problemática, la pedagogía conceptual y la pedagogía intercultural. (Cf. VILCATOMA, $2007: 58$; FACULTAD DE EDUCACIÓN A DISTANCIA, 11-15).

Las propuestas pedagógicas se divisaron en cuatro sistemas educativos peruanos (Cf. GALLEGOS, 2 009:5): 1) Sistema tradicional (Ley No 9 359), 2) Sistema de reforma educativa (Decreto Ley $\mathrm{N}^{\circ} 19$ 326), 3) Sistema educativo reformado (Ley $N^{\circ} 23384$ ) y 4) Sistema educativo actual (Ley $N^{\circ} 28044$ ), cada uno de ellos tienen características propias y una visión panorámica de la problemática de la educación peruana. 
Acerca de la realidad universitaria, debemos recodar la reforma universitaria cordobesa de 1918 , el entusiasmo de la juventud universitaria, convirtió el Grito de Córdoba en un panegírico simbólico del estudiante, que implico la renovación de métodos de enseñanza y la intensificación de los estudios, su expresión ideológica trasunto en el movimiento estudiantil peruano de 1919 , la sombra de estos movimientos aún de cierta forma perviven en el pensamiento universitario. (Cf. SUPO, 2 005:19, MARIÁTEGUI, 1973:142).

Referente a legislación universitaria, la conquista de nuevos espacios de libertad en la vida universitaria, se ha dado de manera anacrónica, en paragón con otros países como Argentina, Uruguay y Cuba, la preocupación de los Estados latinoamericanos es poco vigoroso; es cierto que la América Latina de los años ochenta se ha dado la instalación de un Estado "precario», que ha conllevado una brutal ofensiva en contra de la educación pública (Cf. CARBONELL, 2 004:340); los cambios políticos han lenificado el pensamiento crítico, y el poder comunicativo logro desviar la atención a los derechos de los estudiantes hacia asuntos de interés comercial y político, evitando discusiones entorno al contenido esencial de la educación y sus dimensiones, ello con la complacencia de la actual legislación universitaria. En esta trama, el estudiante pretendió cobrar mayor protagonismo social y relevancia jurídica, lo que hoy se plasma en el interés superior del estudiante contenida en la Ley N 30220 «Ley Universitaria».

Los antecedentes ligeramente expuestos, me permiten discurrir dos modelos que describe la realidad existencial del estudiante, estos son:

a) El modelo de la opresión: Los estudiantes, son seres despojados de su humanidad, objetos inanimados de tratamiento y control constante (Cf. FREIRE, 1987:30, 40, 46) y el profesorado, es agente fundamental de la educación (Art. 30 Ley N ${ }^{0} 23384$.Derogada), la llamada pedagogía del oprimido (concepción bancaria de la educación), que sustancialmente considera al estudiante un mero recipiente del saber, y lo denomina: alumno.

b) El modelo de la liberación: El estudiante es el centro del proceso y del sistema educativo (Art. 53 ${ }^{\circ}$ Ley $N^{0} 28$ 044), la llamada pedagogía del humano libre; Ernani Maria FIORI, bajo la misma línea, profiere: "Los caminos de la liberación son los del mismo oprimido que se libera: él no es cosa que se rescata sino sujeto que se debe auto-configurar responsablemente.» (FREIRE, 1987:7), bajo este modelo, el alumno es denominado: estudiante.

A decir del educador y abogado brasileño, Paulo FREIRE, la pedagogía humanista y liberadora tiene dos momentos, el primero, en el cual los oprimidos van descubriendo el mundo de la opresión y se van comprometiendo, en la praxis, con su transformación $y$, el segundo, en que una vez transformada la realidad opresora, esta pedagogía deja de ser del oprimido y pasa a ser la pedagogía de los hombres en proceso de permanente liberación.(1 987:41)

El esclarecimiento de las contradicciones de la sociedad por la pedagogía crítica y la perspectiva humanista de FREIRE, se unen en un discurso mitificante del estudiante que ha enarbolado el principio del interés superior del estudiante, sujeto emancipado de la estructura de opresión, el cual puede autoconfigurarse como un ser existencial en el sistema educativo consecuentemente reclamar atención a sus intereses cuando la autoridad educativa toma cualquier decisión que pueda afectarle.

\section{Gráfico $\mathrm{N}^{\circ} 01$}

Modelos sobre el tratamiento del estudiante

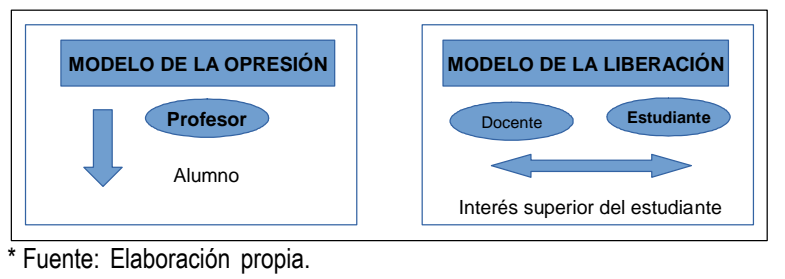

\subsection{El interés superior del estudiante}

El artículo $5.14^{\circ}$ de la Ley $N^{\circ} 30220$ «Ley Universitaria» enuncia que las universidades se rigen por el «principio del interés superior del estudiante», concepto nuevo y dinámico, al cual permítaseme definirlo, como aquel que tiene como consideración primordial atender el interés del estudiante en todas las medidas concernientes a los estudiantes que tomen las universidades bajo cualquier modalidad, sean públicas o privadas, nacionales o extranjeras, que funcionen en el territorio peruano. 
Por su parte, el abogado y Congresista Yonhy LESCANO, sostiene que este principio «quiere decir que la educación tiene como esencial objetivo atender el interés de los jovenes que estudian en las universidades, de formarlos para ser profesionales al servicio del país, por eso son ellos la razón de laexistencia de estos centros de educación superior.(sic)»(2 014).

La autoridad universitaria, docentes y personal no docente y demás agentes jurídicos deben interpretar y aplicar el interés superior del estudiante a fin de subvenir la educación y garantizar los derechos que les corresponden; el contenido del interés superior del estudiante debe ajustarse y definirse de forma individual, con arreglo a la situación concreta del estudiante 0 estudiantes afectados y teniendo en cuenta el contexto, la situación y las necesidades personales; y en decisiones colectivas se debe evaluar y determinar el interés superior del estudiante en general atendiendo a las circunstancias del grupo concreto 0 estudiantes en general.

El «objetivo del interés superior del estudiante» es garantizar el disfrute pleno y efectivo del derecho a la educación y de todos los derechos reconocidos por la Constitución, el derecho internacional de los derechos humanos, y la Ley Universitaria, que constituyen el marco jurídico para lo toma de decisiones que afectan al estudiante o estudiantes en las universidades públicas o privadas. El derrotero del interés superior exige una dogmática fluida, donde los elementos constitutivos se relativicen a fin de conectar el derecho interno y el derecho internacional, con el fin de darle mayor amplitud de aplicación, empero, no debe considerarse el interés superior, como un mero instrumento, un tubo de escape ante cualquier duda, está de debe ser razonable, sí, una duda razonable que observe la coherencia y convivencia de varios derechos, por ello la dogmática fluida demanda una moderación para llegar a una idea central. (Cf. ZAGREBELSKY, 2 011:17-18)

El interés superior del estudiante, tiene tres "dimensiones»: (a) Un derecho sustantivo: el derecho del estudiante a que su interés superior sea una consideración primordial que se evalúe y tenga en cuenta al examinar distintos intereses para tomar una decisión sobre una cuestión debatida, y la garantía de que ese derecho se pondrá en práctica siempre que se tenga que adoptar una decisión que afecte al estudiante, a un grupo de estudiantes concreto o genérico; (b) Un principio jurídico interpretativo fundamental: si un texto normativo admite más de un sentido interpretativo, se elegirá el significado normativo atribuido o descubierto que satisfaga de manera más efectiva el interés superior del estudiante, o cuando dos o más normas regulen el mismo hecho, se elegirá aquel que favorezca al estudiante, según las posibilidades del juego interpretativo (Vid. GUASTINI, 1 999:16-17); (c) Una norma de procedimiento: siempre que se tenga que tomar una decisión que afecte a un estudiante en concreto, a un grupo de estudiantes concreto 0 a la generalidad de estudiantes, las decisiones deberán respetar las garantías procesales sopesando las posibles repercusiones (positivas o negativas) de la decisión en el estudiante o los estudiante interesados, esto es, que las autoridades universitarias deberán explicar cómo se ha respetado el interés superior del estudiante en la decisión, señalando los criterios en que se ha basado la decisión y cómo se han ponderado los intereses del estudiante frente a otras cuestiones normativas generales o particulares.

En la praxis el interés superior del estudiante, busca el beneficio del estudiante en las decisiones administrativas, académicas y otras medidas como la aprobación de reglamentos, directivas, políticas, estrategias, programas, planes, presupuestos, relativas a los estudiante en general o a un determinado grupo de estudiantes.

\section{Gráfico $N^{\circ} 02$}

\section{Dimensiones del Interés superior delestudiante}

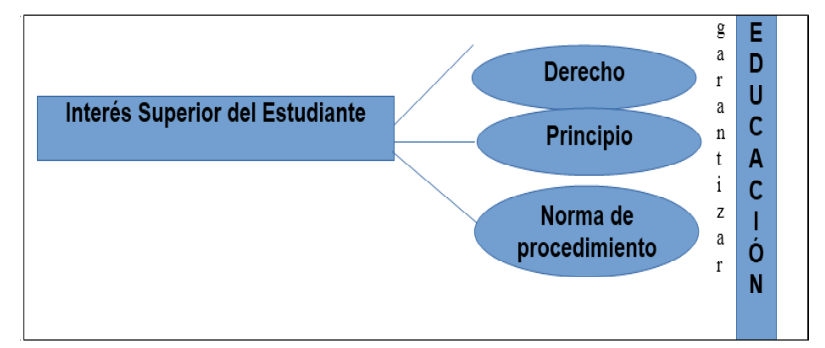

*Fuente: Elaboración propia.

\subsection{El interés superior del estudiante y su relación con los derechos fundamentales}

El interés superior del estudiante, tiene por fuente 
constitucional el artículo 13 de la Constitución, referido al derecho a la educación y el párrafo 2 del artículo 13 del Pacto Internacional de Derechos Económicos, Sociales y Culturales, referido al derecho a recibir educación, bajo esa premisa, el interés superior se presenta como norma sustantiva, principio y norma de procedimiento que tiene relación con varios derechos fundamentales referidos a la educación, pues estos son concomitantes en su aplicación; sin intención de soslayar derechos implícitos o no enumerados, se mencionan a continuación algunos contenidos en nuestra Constitución peruana y el corpus juris del derecho internacional de los derechos humanos:

\subsubsection{El derecho a la educación (artículo $13^{\circ}$ de la Constitución y del Pacto Internacional de Derechos Económicos, Sociales y Culturales)} Las autoridades, los docentes y personal no docente, al evaluar y determinar el interés superior del estudiante deben garantizar el derecho de educación que a decir del Tribunal Constitucional del Perú (Fundamento 10 de la Sentencia recaída en el expediente $\mathrm{N}^{\circ}$ 04232-2004-AA/TC) este derecho consiste en la facultad de adquirir o transmitir información, conocimientos y valores a efectos de habilitar a las personas para sus acciones y relaciones existenciales y coexistenciales; amén de ser una guía, dirección u orientación para el desarrollo integral de la persona.

La educación es un derecho humano intrínseco y un medio indispensable de realizar otros derechos humanos. Como derecho del ámbito de la autonomía de la persona, la educación es el principal medio que permite a adultos y menores marginados económica y socialmente salir de la pobreza y participar plenamente en sus comunidades. La educación en todas sus formas y en todos los niveles debe tener las siguientes cuatro características interrelacionadas y fundamentales: la disponibilidad, la accesibilidad, la aceptabilidad y la adaptabilidad, y en su correcta aplicación se habrán de tener en cuenta ante todo los superiores intereses de los alumnos. (CF. OFICINA DEL ALTO COMISIONADO DE LAS NACIONES UNIDAS PARA LOS DERECHOS HUMANOS, 1999:1-3).

a) Disponibilidad: Está característica indica que los Estados parte deben contar instituciones y programas de enseñanza suficientes con las condiciones necesarias. V.gr. edificios, instalaciones sanitarias para ambos sexos, agua potable, docentes calificados con salarios competitivos, materiales de enseñanza, bibliotecas, servicios de informática, tecnología de la información, etc.

b) Accesibilidad: Las instituciones y los programas de enseñanza han de ser accesibles a todos, sin discriminación, en el ámbito del Estado Parte. La accesibilidad consta de tres dimensiones que coinciden parcialmente:

i) No discriminación: La educación debe ser accesible a todos, sin discriminación por ninguno motivo.

ii) Accesibilidad material: La educación ha de ser asequible materialmente, ya sea por su localización geográfica de acceso razonable o por medio de la tecnología moderna. V.gr. programas de educación a distancia, instituciones educativas municipales.

iii) Accesibilidad económica: La educación ha de estar al alcance de todos; la enseñanza primaria ha de ser gratuita para todos, y gradualmente la enseñanza secundaria y superior gratuita.

c) Aceptabilidad: La forma y el fondo de la educación, comprendidos los programas de estudio y los métodos pedagógicos, han de ser aceptables para los estudiantes y, cuando proceda, los padres. V.gr. pertinentes, adecuados culturalmente y de buena calidad.

d) Adaptabilidad: La educación ha de tener la flexibilidad necesaria para adaptarse a las necesidades de sociedades y comunidades en transformación y responder a las necesidades de los estudiantes en contextos culturales y sociales variados.

De otro lado, el Tribunal Constitucional del Perú (Fundamentos 17 y 11 de la Sentencia recaída en el expediente $\mathrm{N}^{\circ}$ 04232-2004-AA/TC), sostiene que «la educación se configura también como un servicio público, en la medida que se trata de una prestación pública que explicita una de las funciones-fines del Estado, de ejecución per se o por terceros bajo fiscalización estatal. Por ende, el Estado tiene la 
obligación de garantizar la continuidad de los servicios educativos, así como de aumentar progresivamente la cobertura y calidad de los mismos, debiendo tener siempre como premisa básica, como ya se ha mencionado, que tanto el derecho a la educación como todos los derechos fundamentales (e incluso las disposiciones constitucionales que regulan la actuación de los órganos constitucionales) tienen como fundamento el principio de la dignidad humana.

(subrayado agregado por el mismo tribunal).

\subsubsection{El derecho a la educación universitaria} (artículo $18^{\circ}$ de la Constitución): El interés superior del estudiante abarca el derecho a la educación superior, que comprende los siguientes derechos: a) derecho de acceso a la universidad en condiciones de igualdad, b) derecho a permanecer en la universidad libre de limitaciones arbitrarias, c) derecho a la obtención del título universitario, d) derecho a la libertad científica en la comunidad universitaria, que se manifiesta en el acceso a los locales universitarios o facultades, uso de las aulas, ambientes o servicios con el objeto de participar, desarrollar o fomentar talleres, seminarios, conferencias, u otros formas de debate académico; asistir como estudiante libre a los cursos de su interés, el acceso a bibliotecas u otros centros de información.

\subsubsection{El derecho a no ser víctima de violencia} moral, psíquica o física 0 a tratos inhumanos 0 humillantes (artículo $2^{\circ}$, inciso 24, apartado h de la Constitución): El interés superior del estudiante debe evitar decisiones que afectan la integridad física, psíquica y moral de los estudiantes, V.gr. castigos humillantes.

3.3.4. El derecho a la igualdad (artículo $2^{\circ}$, inciso 2 de la Constitución): Al evaluar y determinar el interés superior del estudiante, debe evitarse obstaculizar o restringir el acceso 0 permanencia en las universidades, y la discriminación por razones de origen, raza, sexo, idioma, religión, opinión, condición económica o de cualquiera otra índole.

\subsubsection{El derecho al libre desarrollo de la} personalidad (artículo $2^{\circ}$, inciso 1 de la Constitución): El interés superior del estudiante, debe cautelar el libre desarrollo de la personalidad, al fijar restricciones al estudiante sin criterio razonable y proporcional. v.gr. apariencia personal.

3.3.6. El derecho al debido proceso (artículo $139^{\circ}$ inciso 2 de la Constitución): El interés superior del estudiante debe garantizar al estudiante todos los principios y reglas del proceso o procedimiento previstas en la Constitución, la Ley Universitaria y el Estatuto. Vgr. la oportunidad de defenderse, presentar pruebas, la imputación concreta en un proceso disciplinario (Art. 101 Ley Universitaria).

\subsubsection{El derecho de los estudiantes de participar} en las decisiones que les afectan en la universidad (artículo $18^{\circ}$ de la Constitución): $\mathrm{Al}$ evaluar y determinar el interés superior del estudiante no debe afectarse el derecho de elegir o ser elegido como representante ante los respectivos órganos de la Universidad.

\subsection{El interés superior del estudiante y su conexidad con otros principios de la Ley Universitaria:}

3.4.1. La calidad académica (Art. $5.2^{\circ}$ y $5.11^{\circ}$ ): Es patente que el interés superior del estudiante trasfunde la calidad académica y su mejoramiento es en provecho de los estudiantes, futuros actores en la transformación de la sociedad, beneficiaria mediata de las altas cualidades de enseñanza y aprendizaje en las aulas universitarias.

Este principio, coincide con en el derecho de los estudiantes de recibir una formación académica de calidad que les otorgue conocimientos generales para el desempeño profesional y herramientas de investigación (Art. 100.1\%).

3.4.2. La autonomía.(Art. 5.3): En toda actuación de la universidad en virtud de su autonomía que le confiere un haz de atribuciones o potestades de régimen normativo, ejecutivo, académico, administrativo y económico; en su ejercicio es menester evaluar y determinar el interés superior del estudiante en el marco de la Constitución y el derecho internacional de los derechos humanos, esto es, no afectar los derechos fundamentales de los estudiante al crear normas, al conducir la institución universitaria, al fijar el proceso de enseñanza y aprendizaje, al implementar sistemas de gestión, al administrar, y disponer del patrimonio institucional; así como para 
fijar los criterios de generación y aplicación de los recursos, para ello la Ley Universitaria estipula garantías para el ejercicio de la autonomía universitaria (Art. $10^{\circ}$ ), reglas que secundan el interés superior del estudiante.

De otro lado, los estudiantes tiene el deber de respetar la autonomía universitaria y la inviolabilidad de las instalaciones universitarias (Art. 99.5\%), a tenor del interés superior, de una simple sindéresis, decanto por flexibilizar este deber para los estudiantes, quienes al recibir la afrenta a sus derechos fundamentales, en atención al interés superior, están habilitados a no observar cualquier decisión arbitraria que vulnere el principio-derecho de dignidad (Art. $1^{\circ}$ de la Constitución).

\subsubsection{La libertad de cátedra. (Art. $5.4^{\circ}$ ): Está} garantía institucional, faculta la discrecionalidad sobre un asunto ligado a la asignatura del docente, este ejercicio no debe ser dogmático, por el contrario el interés superior del estudiante, garantiza el derecho a la discrepancia en el cual subyace la tolerancia, el respeto y el derecho a ser oído con la debida atención y resolución a los cuestionamientos planteados por el estudiante.

3.4.4. La democracia institucional (Art. 5.6 $6^{\circ}$ ): El interés superior del estudiante se extiende a la democracia universitaria, garantizando la participación de los estudiantes en procesos electorales, de investigación, económicos, culturales, etc, atendiendo su opinión.

Este principio se apoya en el deber del estudiante de respetar la democracia (Art. $99.7^{\circ}$ ) y el respectivo derecho de participar en el gobierno y fiscalización de la actividad universitaria, a través de los procesos electorales internos, de acuerdo a Ley Universitaria y la regulación que establezca cada universidad (Art. $\left.100.5^{\circ}\right)$.

3.4.5. La meritocracia (Art. 5.7 ${ }^{\circ}$ ): Toda reconocimiento, felicitación o estimulo en la comunidad universitaria, debe propender la atención de los intereses de los estudiantes, mediante su evaluación y determinación, ello también implica flexibilizar del deber del estudiante de aprobar las materias correspondientes al periodo lectivo que cursan (Art. $99.2^{\circ}$ ), según el caso concreto, dado que el interés superior debe garantizar el derecho a la educación, derecho humano inherente, para el cual no existe mayor óbice que la dignidad humana, amén, la educación se encuentra en el ápice del interés superior, considerando que el estudiante es la razón de ser de la Universidad.

\subsubsection{El pluralismo, tolerancia, diálogo} intercultural e inclusión (Art. 5.8 ${ }^{\circ}$ ): Las decisiones adoptadas sobre aceptación, reconocimiento, convivencia y dialogo con el otro, debe fundamentarse en el interés superior del estudiante, escatimando en cada caso particular la realidad de cada estudiante decantando en lo más favorable para él. V.gr. un estudiante con discapacidad o de otra cultura, requiere una evaluación y determinación de sus intereses que facilitaran el ejercicio de todas sus facultades.

\subsubsection{La afirmación de la vida y dignidad humana} (Art. $5.10^{\circ}$ ): Toda actuación de la Universidad debe respetar la vida y la dignidad humana, máxime, la de los estudiantes, toda política o plan de desarrollo debe reafirmar este principio buscando el interés del estudiante, es una cuestión ineludible.

\subsubsection{La internacionalización (Art. 5.13 $)$ : El} proceso de relacionarse con universidades extranjeras, debe conseguir atender el interés del estudiante. V.gr. convenios entre universidades para el intercambio de estudiantes.

\subsubsection{La pertinencia de la enseñanza e} investigación con la realidad social (Art. $5.15^{\circ}$ ): La evaluación y determinación del interés superior, debe enfocarse en la realidad social del estudiante 0 estudiantes. V.gr. un universitario puneño debe recibir formación sobre la realidad latinoamericana, nacional, regional, y el idioma originario (quechua o aymara) a fin de facilitarle el trabajo de campo al realizar investigaciones y la comunicación con otras culturas.

\subsubsection{El rechazo a toda forma de violencia,} intolerancia y discriminación (Art. 5.16 ${ }^{\circ}$ ): Cualquier decisión de la autoridad, docente y personal no docente, debe cautelar la seguridad, integridad e igualdad de los estudiantes considerando el interés superior, a fin de ofrecer al estudiante un ambiente de paz y sosiego. V.gr. El Rector, de presentarse hechos violentos, apriori debe considerar el interés superior del estudiante para peticionar el 
ingreso de las fuerzas pública, este principio es consustancial a la vida y la dignidad humana.

De otro lado, este principio tiene por correlato el deber del estudiante de practicar la tolerancia, y rechazar la violencia (Art. 99.7\%).

\section{Gráfico $N^{\circ} 03$}

El interés superior del estudiante: parabólica que enlaza los derechos fundamentales (DF) y los principios de la Ley Universitaria (PLU)

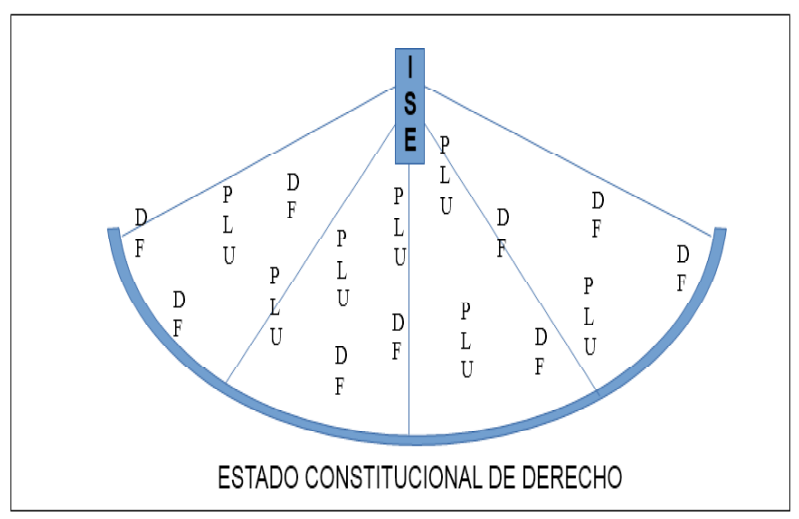

* Fuente: Elaboración propia.

\subsection{Aplicación}

Se preconiza que la evaluación y la determinación del interés superior del estudiante son dos pasos que deben seguirse cuando haya que tomar una decisión que le afecte a este centro del proceso educativo y razón de ser de las Universidades y de las instituciones educativas de cualquier nivel.

\subsubsection{La evaluación del interés superior: Consiste} en valorar y sopesar todos los elementos 0 circunstancias necesarias para tomar una decisión en una determinada situación para cada estudiante 0 grupo de estudiantes o estudiantes en general. Esas circunstancias se refieren a las características específicas del estudiante o estudiantes, estos tienen un contenido concreto y son susceptibles de ser ponderados. V.gr. la edad, el sexo, la experiencia, la pertenencia a un grupo minoritario, la existencia de una discapacidad, el contexto social y cultural, el rendimiento académico, las actitudes, el semestre 0 nivel al cual pertenece, la situación económica, la opinión del estudiante, la preservación de la matrícula, etc; es conveniente elaborar una lista de elementos, y considerar otros factores para el caso concreto, y requerir la participación del estudiante.
Los elementos tomados en cuenta no deben contradecir los derechos fundamentales consagrados en la Constitución y el Derecho Internacional de los Derechos Humanos.

Uno de los elementos a tomarse en cuenta para la toma de decisiones es «la opinión del estudiante», que consiste en invitarle y permitirle al estudiante expresar su opinión sobre cualquier decisión que le afecte. V.gr. recibir la opinión acerca del modo de evaluación, los contenidos de las asignaturas, el docente quien dictará determinado curso, los horarios, la adquisición de bibliografía, la programación de eventos, actualización de la estructura curricular (plan de estudios), programación de eventos, reformas legales (reglamentos, normas de convivencia), etc.

Se puede aducir que la «opinión del estudiante», es un elemento basilar para la evaluación y determinación del interés superior, el cual permite afianzar varias características deseables de los estudiantes: identidad personal, estilo de vida democrático, capacidad creativa y critica, decisión, autonomía, asertividad, aprendizaje, formación ética y moral, formación profesional, emprendimiento, etc, dicho de otro modo, la opinión del estudiante, lo fortalece, lo erige como ciudadano libre que ayuda a formar la voluntad general del Estado Constitucional, consecuentemente, será un protagonista en el desarrollo y protección de la Sociedad, en otra palabras, el interés superior debe permitir al estudiante forjarse en la Universidad según el perfil profesional deseado.

3.5.2. Determinación del interés superior: Se entiende el proceso estructurado con garantías estrictas, concebido para determinar el interés superior del estudiante tomando como base la evaluación del interés superior. (Cf. supra).

La determinación del interés superior del estudiante tiene su correlato con las garantías procesales para velar por la observancia del interés superior del estudiante, estos son: la opinión del estudiante, la determinación de los hechos, la argumentación jurídica, la evaluación del impacto en los derechos del estudiante, cabe precisar que estás consideraciones han de aplicarse entorno a los derechos y deberes del estudiante debidamente 
acreditado dentro del ámbito universitario, caso contrario, cualquier otro asunto debe tratarse de forma ordinaria.

Atinente a los derechos del estudiante, según el artículo $133^{\circ}$ de la Ley Universitaria, la instancia encargada de la tutela de los derechos de los miembros de la comunidad universitaria es la Defensoría Universitaria, quien es competente para conocer las denuncias y reclamaciones que formulen los miembros de la comunidad universitaria vinculadas con la infracción de derechos individuales.

\section{Gráfico $\mathrm{N}^{\circ} 04$ \\ Evaluación y determinación del interés superior del estudiante}

\begin{tabular}{|lll|}
\hline $\begin{array}{l}\text { Elementos } 0 \\
\text { circunstancias del } \\
\text { estudiante }\end{array}$ Proceso con reglas y & Principios & S \\
& & E \\
\hline
\end{tabular}

Fuente: Elaboración propia.

3.6. Difusión e investigación. Cuestión final: Es menester divulgar el principio del interés superior del estudiante por tratarse de un instrumento inexorable que encausa las decisiones que pueden afectar al estudiante, grupo de estudiantes o estudiantes en general, más aún cuando su aplicación garantiza el derecho a la educación, pilar fundamental de la sociedad, sin el cual no logramos el perfeccionamiento personal, la reflexión acerca del yo y del otro, la edificación de un pensamiento liberador con identidad nacional y latinoamericana, sin la educación tan solo obtenemos la tenue opinión de una realidad inacabada, somos expuestos al señorío de los grupos de interés que gobiernan a las naciones de la periferia, en efecto, un pueblo ignorante es una grey en medio de lobos, en consecuencia, la difusión del interés superior del estudiante es una tarea pendiente en nuestro país; de igual modo, es necesario que los agentes jurídicos reseñen el interés superior, esas investigaciones deben orientar las decisiones jurisdiccionales en cualquier ámbito de aplicación, en todo caso, la atención a estas necesidades contribuyen en conseguir la justicia social y el respeto absoluto de la dignidad humana, presupuestos para consolidar un ciudadanía activa en las causas del Estado
Constitucional que subviene para establecer un orden jurídico y cultural basado en los derechos humanos, evitando cualquier anquilosamiento en la obtención de nuevos espacios de libertad en un sistema horizontal, esto vislumbra una educación pública, accesible y abierta, libre de la obliteración de los derechos fundamentales, practicante de los derechos humanos. (Cf. RAMIREZ, 2 008:114; HÄBERLE, 2 003:5).

\section{CONCLUSIONES}

4.1. El interés superior del estudiante, es aquel que tiene como consideración primordial atender el interés del estudiante en todas las medidas concernientes a los estudiantes que tomen las universidades bajo cualquier modalidad, sean públicas 0 privadas, nacionales o extranjeras, que funcionen en el territorio peruano.

4.2. El objetivo del interés superior del estudiante, es garantizar el disfrute pleno y efectivo del derecho a la educación y de todos los derechos reconocidos por la Constitución, el derecho internacional de los derechos humanos, y la Ley Universitaria, que constituyen el marco jurídico para lo toma de decisiones que afectan al estudiante o estudiantes en las universidades públicas o privadas.

4.3. El interés superior del estudiante se manifiesta en tres dimensiones: como derecho sustantivo, principio jurídico interpretativo y norma de procedimiento.

4.4. El interés superior del estudiante, es un concepto parabólico que mantiene una conexidad con los derechos fundamentales reconocidos en la Constitución y el Derecho Internacional de los Derechos Humanos y los principios de la Ley Universitaria.

4.5. La aplicación concreta del interés superior del estudiante, requiere la evaluación del interés superior, consiste en valorar y sopesar todos los elementos 0 circunstancias necesarias para tomar una decisión en una determinada situación para cada estudiante o grupo de estudiantes o estudiantes en general. $Y$ la determinación del interés superior, en aquel proceso estructurado con garantías estrictas, concebido para determinar el interés superior del 
estudiante tomando como base la evaluación del interés superior.

\section{REFERENCIAS BIBLIOGRÁFICAS}

5.1. CARBONELL, Miguel (2 004).Los derechos fundamentales en México. México. Instituto de Investigaciones Jurídicas.

5.2. FACULTAD DE EDUCACIÓN A DISTANCIA. Módulo didáctico: Pedagogía de la equidad y la solidaridad. Chosica. Universidad Nacional de Educación Enrique Guzmán y Valle.

5.3. FREIRE, Paulo (1 987). Pedagogía del oprimido. Lima.s/e.

5.4. GALLEGOS VALDEZ, Vitaliano (2 009). Compendio Pedagógico Actualizado $\left(8^{\circ}\right.$ ed.).Arequipa. s/e.

5.5. GUASTINI, Riccardo (1 999). Estudios sobre la interpretación jurídica. Traducción de Marina Gascón y Miguel Carbonell. México. Instituto de Investigaciones Jurídicas.

5.6. HÄBERLE, Peter (2 003). El estado constitucional. Traducción de Héctor Fix-Fierro. México. Instituto de Investigaciones Jurídicas.

5.7. LESCANO ANCIETA, Yonhy (2 014) Consulta sobre el interés superior del estudiante. Correo electrónico del 22 de julio de 2014 a Michael Espinoza Coila.

5.8. LÓPEZ DURÁN, Rosalío (2 002). Metodología Jurídica. México. lure Editores.

5.9. MARIÁTEGUI, José Carlos (1 973). 7 ensayos de interpretación de la realidad peruana $\left(26^{\circ}\right.$ ed.). Lima. Empresa Editora Amauta.

5.10. MUÑOZ, Vernor (2 008) «Un mar en la niebla: apuntes para una nueva educación» En RAMIREZ, Gloria (Coordinadora). Los derechos humanos en las sociedades contemporaneas. México. Fondo Editorial de Nuevo León.

5.11. NACIONES UNIDAS (2 013). Observación general No 14 (2013) sobre el derecho del niño a que su interés superior sea una consideración primordial (artículo 3, párrafo 1). s/c.s/e.

5.12. OFICINA DEL ALTO COMISIONADO DE LAS NACIONES UNIDAS PARA LOS DERECHOS HUMANOS (1 999). El derecho a la educación (Art. 13): 08/12/99 CESCR Observación general $N^{\circ} 13$. s/c.s/e. Consulta: 09 de agosto de 2014. <http:// www.acnur.org/biblioteca/pdf/3591. pdf?view=1>.

5.13. REAL ACADEMIA ESPAÑOLA (2 003). Diccionario de la lengua española $\left(22^{\circ}\right.$ ed.). Ed.
Espasa Calpe, S.A. España.

5.14. SUPO CONDORI, Felipe (2 005). Pautas para la reforma universitaria en la UNA-PUNO. Puno. Editorial Universitaria.

5.15. VILCATOMA SALAS, Luis et al (2 007). Módulo I: Enfoques educativos. Puno. Universidad Nacional del Altiplano.

5.16. WITKER, Jorge y LARIOS, Rogelio (1 997). Metodología Jurídica. México. McGraw-Hill.

5.17. ZAGREBELSKY, Gustavo (2 011). El Derecho dúctil: Ley, derechos, justicia. Traducción de Marina Gascón Abellán. Madrid. Editorial Trotta.

\section{LEGISLACIÓN}

6.1.CONGRESO DE LA REPÚLICA (1982). Ley $N^{\circ}$ 23384 «El Gobierno promulgó la Ley General de Educación» (derogado). 20 de mayo de 1982.

6.2. CONGRESO DE LA REPÚLICA (2003). Ley $N^{\circ}$ 28044 «Ley General de Educación».29 de julio de 2003.

6.3. CONGRESO DE LA REPÚLICA (2014). Ley $N^{\circ}$ 30220 «Ley Universitaria».09 de julio de 2014.

\section{JURISPRUDENCIA}

7.1. Larry Jimmy Ormeño Cabrera contra la Universidad Privada de Tacna (2005) Tribunal Constitucional del Perú. N04232-2004-AA/TC (acción de amparo). Lima. Consulta: 06 de agosto de 2014. <http://www.tc.gob.pe>. 